\title{
LECTURAS, HOMBRES Y DEMOCRACIAS: LA SINGULARIDAD DEL PLURAL*
}

Eliana Yunes ${ }^{1}$

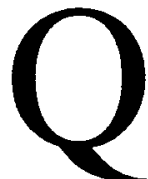

uiero comenzar haciendo notar que las palabras que componen el titulo de esta ponencia están en el plural: al revés de lo que sería razonable, según la filosofia. Más adelante entenderán porque insisto en señalar esta opción. Y también es opción ponerme, en el tema de la lectura, contra la corriente: a mi juício, la lectura no se produce después de la escritura; al contrario, la lectura antecede a la escritura, pues para escribir el mundo es necesario leerlo antes.

Un niño al dibujar, antes de saber escribir, no hace cosa distinta que registrar lo leído: la imagen que pinta es también una forma gráfica, un lenguaje que hace un registro - una y otra cosa corresponden a un mismo eje, lo de la expresión - bajo ciertos signos que, aparentemente, se vuelven fijos en el papel. En ambos casos, les antecede la exigencia de que el escritor o el ilustrador ya haya hecho una lectura de mundo, incluyéndose en él, al ubicarse en un punto - de vista - para presentar lo que "ve". Así, primero leemos el entorno, el contexto, la situación y

* Conferência en el $1^{\circ}$ Simpósio de Lectura de Cali, Colombia, oct. 1999 Transcripción de Constanza Cardona.

1 Pontifícia Universidade Católica do Rio de Janeiro. 
solamente más tarde, leemos los lenguajes formales, es decir, los que tienen reglas y normas - sintaxis y combinaciones semánticas- definidas "a priori".

Quien no lee no es capaz de escribir en idioma alguno, ni en los idiomas llamados "naturales" - español, alemán o chino - ni siquiera leer otros sistemas o códigos, como los del cuerpo en la danza; los del trazo y el volumen en el espacio; pintura, escultura, arquitectura; la ubicación del ojo en la fotografía, en el cine y aun con lenguajes mas insospechados como los del vestuario, de la publicidad, del trazado de las ciudades, el del comportamiento social.

Esto se comprueba desde la más tierna edad: cuando el niño es amamantado o acunado en los brazos de la madre, percibe sus tensiones, sus inseguridades, su alegría. A los cinco años un niño que, por ejemplo, sale a jugar en los charcos formados por la lluvia y ensucia sus ropas, antes de decidirse a cruzar la casa en dirección al baño necesita percartarse del humor de su madre; si ella está cantando, el peligro de oír reprimendas y, quien sabe, sufrir un castigo peor, será menor. Todo el tiempo estamos leyendo - leer es una condición de sobrevivencia. A los hombres que no leen, y no solamente lo escrito, no les es fácil sobrevivir.

Claro está que lectura en la acepción amplia que estoy proponiendo no trata solamente de leer las señales del tiempo para decidir -cuando es posible escoger- si me abrigo más o menos cada mañana al salir de casa, si llevo el paraguas o no. Lectura es una práctica obligatória para todas las cosas que hacemos: con cada persona que nos encontramos, és preciso emprender una lectura como un aprendizaje, pues estamos delante de un "texto" nuevo, desconocido. De ahí que convivir sea tan sutil, lleno de matices; en general tenemos lecturas pre-concebidas que no nos dejan ver sino lo que queremos o podemos ver en el otro, ya que nuestro texto personal es el que nos sirve de referencia. Para leer con nuevos horizontes, somos invitados a salir de nosotros mismos, relativamente, para penetrar lo desconocido, sin quedarnos sólo en lo que es aparente. Tomar los prejuicios nuestros como lecturas es como tener respuestas listas antes de conocer los textos.

Esto ocurre con frecuencia en las escuelas y dificulta el aprendizaje de la lectura. En general, el niño lee el mundo con mucha espontaneidad y con la confianza de su experiencia. Cuando cruza la puerta del salón de clase tiene la sensación de que ya no entiende nada, porque ahora el mundo es prisionero de otro lenguaje, el lenguaje codificado, sin su participación y consentimiento. El niño percibe que el mundo, o mejor la vida ahí registrada, trae marcas de ciertos valores, cierta época, ciertas condiciones sociales de los que la usaron (y la fijaron) antes de él, de los que hicieron acuerdos sobre la expresión, los arreglos de la secuencia, las imágenes, el ritmo. Situación que le exigiría al niño tener alguna vocación para hacer ejercicios de detective o tener el gusto por las novelas policíacas para "descubrir" lo que se oculta por detrás del mundo de lo escrito, donde todo exige desciframiento: pero como reconocer la "letra", si el mundo que se oculta por detrás de ella no incluyó para nada al lector virtual? 
Así la escrita, esta práctica tan cara a nuestra civilización, parece aprisionar al mundo y también como en una fotografía, lo paraliza. Allí se crea un vacío entre el posible lector y el texto. En general, él no se siente capaz de saber, por cuenta propia o riesgo, cuál es el sentido de tal lenguaje. También se paraliza a la espera de que alguien le enseñe, explique el texto cifrado, ya que el autor ausente, no faculta la práctica de los diálogos que le permitieron a Sócrates, según Platón, fundar la filosofía. No quiere correr el riesgo de "entender" aúnque el riesgo sea mágico, que puede revelarnos cosas de nosotros mismos, hasta entonces desconocidas - como un acto de creación revela tanto el creador como lo creado. Y desde el Génesis, somos todos (con-)creadores, aunque solamente se permita a unos cuantos creer en su poder creador, en su servicio a la vida, para transformarla, para completarla como un todo y no exclusivamente en su particularidad personal. Otros fueron conformados a repetir lo que ya fue dicho o hecho antes, como si la tarea, a lo sumo, fuese la de desvelar lo secreto que ahí ya está puesto, sin posibilidades de interactuar, de responder con algo nuevo, aunque parezca desbaratado y loco, en un primer momento.

Por esto en general, el mundo de la escritura parece opaco, sin posibilidad de que la vida viva lo atraviese. La letra sustenta una disecación de su cuerpo pero no una reanimación de su espíritu. El lector ve la letra pero no ve el mundo porque desconoce su disposición de sentido, generada en otro espacio que no es el suyo, del cual desde el inicio, no da cuenta, no reconoce, no atina. En esta concepción de la escritura que guarda el saber estatuido, en que el significado y el sentido se dan antes de la escritura, se confirma lo que yo venía diciendo: hay una lectura que precede al acto de escribir. Suena como si la vida leída estuvise paralizada en la escritura, ya que ella es lo que se ha se ha dicho hace algún tiempo y en algún lugar. Puede incluso convertirse en una experiencia de terror como la que conoció el final de la edad media, con prisiones, torturas y hogueras para quien osara leer por cuenta propia o actualizar lo escrito sagrado o profano, bajo vigilancia. A los letrados, les era posible leer sólo para recordar el significado guardado por el sistema político, bajo un código cerrado a recepciones distintas, impermeable a las ambiguedades. El sentido pre-existía a la escritura (lógico, si había una lectura anterior, dirán todos...) Pero se inmovilizaba y se imponía de ahí en adelante, aunque ya no fuese posible reconocerse una en él... (lógico, diremos todos, séguiendo el registro de las consecuencias): los que habían "ofrendado" lo escrito también podían definir/vigilar lo que las letras guardarían. Estaba condenada la "experiencia" de vivir, leer y pensar cada uno por su cuenta.

El filósofo Platón en Fedro cuenta con todas las letras, el mito del alfabeto que el rey le pide al Dios de la Palabra que le fuese concedido para curar el olvido de los hechos en la memoria de los pueblos. Antes de concederlo, Toth argumenta que le estaría veneno y remedio al mismo tiempo - pharmacon, en griego - pues era como si le ofreciese un cuchillo que fuera solamente la lámina, sin el mango 
¿Por qué ? Porque si de un lado, el alfabeto podía garantizar la memoria del pasado, del otro los hechos iban a grabarse en las piedras, los lienzos, en los papiros, en el barro con los hombres; estos, creyendo en la existencia de un depositario, de un soporte de guardia para lo sucedido, no tratarián más de traerlos consigo, de recordarlos, como etimológicamente nos enseña esta palabra Ya no los tendrían en el corazón, verdadera sede de la memoria. Así se borra la memoria que es algo vivo: que no sólo señala lo que ha pasado sino que lo mantiene vivo en el tiempo que sigue. Vivas son las cosas que constituyen la memoria actual de las personas en sus experiencias, en sus haceres, en sus sentimientos. Si esto no es lo que se agiliza en la lectura, estaremos afirmando que tenemos prejuicios - juicios previos de las cosas - tomados como préstamos de las ideologías y discursos ajenos.

De este modo, la familiaridad que podría alcanzarse con la lectura se pierde: y viene el miedo, la intranquilidad, el disgusto. Siempre se pregunta en estas ocasiones de congresos y simposios "qué se debe hacer para despertar en un niño el gusto por la lectura". Yo, particularmente me pregunto, que hemos hecho para que el niño dejase de tener placer en leer, en ampliar sus horizontes de mundo. Porque todos ellos al principio, viajan por los mundos extraordinarios que las narrativas les ofrecen hasta que, comenzando a leer solitarios y preocupados, sea por el código que vela la palabra o por la imposición de los cuestionarios, se alejan y pierden el gusto de leer. Descubren en la práctica que no saben nada, que hay una respuesta correcta con la que no atinan, detrás de cada pregunta. El niño que solía pensar sin saberlo sabe ahora que no consigue pensar y no ve medios para comenzar a hacerlo. Es como si se deshumanizara.

Esto ocurre porque al decretar cómo se piensa, también decretamos lo que es humano, lo que es propio del hombre genéricamente y luego firmamos bajo la intolerancia con la diferencia. Con esto se establece lo que voy a llamar de democracia instrumental, definida por un contrato social, regido por leyes obligatoriamente acatables, inclusivo bajo pena de castigo. Ella nos ofrece una ciudadanía legal que desconoce las condiciones de su práctica. "Morimos" por la democracia y ella no nos representa: ella es instrumental y bien vale la pena preguntar "quien maneja el instrumento?". Toda la liberación que alguien, entonces, imagina poder alcanzar con el conocimiento desaparece en el aire. Lo humano de las leyes no contempla al hombre vivo, en las normas, sistemas y regímenes democráticos, tallados en su nombre, en defensa de sus derechos. Experimentamos con frecuencia una democracia virtual que nada tiene que ver con las posibilidades del venir a ser, sino con lo ilusorio, con lo inefectivo.

En la histaria de las narrativas, verificamos que fueron las literaturas que crearona los pueblos. No es posible pensar en los griegos sin aproximarse a Homero - que no era Herodoto, el historiador. En aquellas historias, no solamente están los hechos realizados por sus héroes, con los cuales se identificaron, sino que también están los afectos, las experiencias, las lecturas e incompreensiones que los 
atravesaban, al escucharlas. Y crearon, para ellos y para nosotros ciertas ideas sobre la "grecidad", como la nuestra literatura habla de una latinoamericanidad.

Si saltamos al siglo XIX, la literatura de nuevo aparece como fundadora no de pueblo sólo, sino de naciones, en el sentido de Estado que no tuvo pudor de llamarse absolutista hasta que, arruinado, ensayó a partir del siglo XVIII, volver a ser democrático: esto es, derecho de todos a todo. Ya entre los griegos, "todos" excluía a mujeres, esclavos y niños.

Con el liberalismo y la burguesía, la literatura se toma el compromiso de hacerse un modelo de nación y de individuo - referencia para la formación social con sus jerarquías - bajo la ilusión del iluminismo que veía lo humano apenas en lo instruido según sus "luces"; bajo la concepción positivista que reconocía como imaginario todo lo que estuviera fuera el dominio de las normas, de las reglas, del experimento. Aunque intentara expressar esta crisis, la literatura se vio muchas veces estrecha, cercenada por el protagonismo de las ciencias con sus medidas y exactitudes al excluir al hombre, temido como impreciso, más allá de las medidas biológicas; como voluble, sin el rigor de la disciplina y de la ley; como irreconocible en su deseo, en su ansia por mejores hechos (muy pronto apuntada como enfermedad): son expresivos los relatos de Mme Bovary a enloquecer en el siglo XIX, considerada histérica, mientras denuncia la represión de la muyer en aquel tipo de sociedad; como el Quijote, siglos antes parecía ser un payaso, cuando era el (único) lúcido en medio a la brutalización que se avecinaba. Pero justificación parecía haber para el contrato social burgués, buscando normatizar a la sociedad a través de los conceptos de individualidad, de derecho y deber ante la ley, garantía instrumental de la igualdad, de la libertad, aunque sin cualquier resquicio, (digo yo), de fraternidad. Llegamos al ápice de la razón instrumental que, con toda ciencia (sin conciencia, dirá Morin), se volvió al recurso justificado de la dominación (como dijo Foucault).

Incluso en situaciones específicas, como en la del reconocimiento del derecho a la alfabetización y a la educación de las masas, no se discutió cuál educación se les debería proporciona ya que obviamente serviria a que pudiese adecuarse y mantener las nuevas estructuras de poder, practicar lo que la razón instrumental reconocía como lo bueno. Aparecen con nitidez los modelos de comportamiento, de rechazo, de exclusión y desde entonces los libros ejemplares, de nobles biografías a los "cómo ser feliz", "cómo ganar dinero sin hacer esfuerzo" - las recetasdominaron las prácticas sociales. Aunque la educación tenga su origen formal ya en los monasterios pre-renacentistas, el auge de su discusión está en el siglo XIX, justamente por el esfuerzo iluminista de aclarar a las masas ignorantes, vale acordarnos ahora, desmemoriadas porque alejadas de su própia experiencia. La educación será por lo tanto, algo que alguien debe recibir y asimilar, como si cada uno de nosotros fuera sólo una porosidad para absorber ciertas visiones del mundo, o sea, lecturas "correctas" del mundo. 
Sería bueno recordar que la palabra educación viene de ex-ducere, es decir, conducirse afuera, aparecer, dar a ver al sujeto; no un ejercicio de "Ilenar" a las personas de informes y datos; facilitarle a que saque toda su potencia de ser, de interactuar con el mundo y de ahí construirlo en un proceso interactivo; no la mera repetición de ocurrencias extrañas a su vida.

Claro está que la vida de cada uno no se agota en los límites de su mirada sino que se extiende al alcance de su lenguaje, segín Wittgenstein. Quien no ejercita de propia voz, de propio puño su palabra, será un imitador, no un creador, un copiador, no un escritor. A título de provocación yo diría que mundo, mundo, no hay: claro que su materialidad física está ahí; pero inerme, ella lo nos sirve para la contemplación sólo. En la acción del hombre es que se dibuja la realidad y la acción del hombre es VERBO. Al dar nombre a las cosas, como nos ordenó Aquel de quien somos a semejanza creadores, las llamamos a la vida, a nuestra vida. Al darle nombre a alguien, lo que hacemos es llamarle de la "inexistencia" a la "existencia". La llamada en el salón de clases no debería ser la lectura de una relación para control de asistencia, sino un ruego al diálogo sobre el conocimiento. A veces, el nombre propio de una persona no le es propio y al llamarlo de aquel modo, nombramos la cáscara en que el sujeto se oculta, o que lo recoge. Si la educación es ayudar-lo a conducirse afuera, no puede ser para colocarlo en una forma idéntica a tantas otras, modelándolo según un patrón de una llamada mecánica.

Esta reflexión, en esta direccíon, afecta la a idea de democracia, que no puede "colocar a todos bajo la visión de mundo y voluntad de uno solo", o de un grupo que tiene el poder de decir cuál debe ser la voluntad de cada uno. Y aunque manejemos con mucha habilidad nuestras elecciones y representaciones, siempre hay probabilidades de equívocos porque la cáscara no es el hombre y cl nombre propio puede llegar a ser "impropio", como la representación del pueblo que se realiza en la política. En este sentido, el lenguaje con sus estructuras demarcadas, afectadas por el uso marcado, puede ser un constrangimiento - de ahí el hecho de que los poetas, escritores ignoraran las normas gramaticales, porque quieren decir más de lo que el lenguaje ya dice; a pesar de que el linguaje diga automáticamente algunas cosas, el poeta quiere desautomatizar la lengua, sueño de todo hombre que, en el fondo querria inaugurar el mundo, si supiera que lo puede hacer.

Así, las certezas positivistas de "orden y progreso" nos han servido muy poco. Pues una y otro son concepciones encerradas en un punto de vista que a sí mismo tiene como lo mejor-quizás, único.

Hasta ahora, vengo hablando de lectura en el singular, humano en el singular y democracia en el singular. Singular no porque indique algo personal y único; más bien es impersonal, genérico. Es como si nada particular sonara a través de la máscara, de la persona. De la palabra griega que distinguía al actor (al 
actuante) con la máscara por la cual se oía la voz del personaje, a la palabra persona, que guarda la idea de "sonar a través de", hay un largo viaje. Y si estamos en lo impersonal, no hay nada que pueda sonar por la máscara, y conducirse afuera. Tenemos entonces un problema, tal vez varios: la generalización que nivela a los hombres por la ley, los masifica y reduce a un modelo hueco, cuyo relleno es la ideología dominante.

¿Quién nos puede liberar de la palabra impersonal, de la "mismidad" de la lengua, de la lógica metafísica, aristotélica, occidental de que necesitamos, incluso para refutarla, cuando nos obliga a decir cosas ya dichas según sus estructuras ordenadas? Todas las armas que tengo aún están sobre esa poderosa central de la razón que ordena lenguaje y pensamiento de una sola vez. ¿Quién puede, si la voz que no tiene su génesis, sino un origen marcado y podemos repetir sólo, como las grabadoras? Hace falta la persona. Que pueda desnudar la máscara y la palabra para que, desnudas, no tengam que avergonzarse de ser copia; al contrario, para que puedam ser inocentes de nuevo; es decir, sean de nuevo sumergidas en el conocimiento posible (in/noscere), inmersa en la posibilidad de la verdad, múltiple, tolerante, plural. Al contrario del ingenuo (que no tiene genio, percepción, ingenio), del inocente conoce el todo, potencialmente.

Cómo usarlo es otra cuestión. Usarlo significa estar en una situación concreta para escoger y decidir el uso de lo que potencialmente dispone y al actualizarlo, saber hacerlo, experimentar, con el propio cuerpo y lenguaje, con la propia voz y memoria. Es necesário que la palabra pierda la ingenuidad que la hace parecer tonta, es necesario que la palabra retome el poder creador que nos autorizó míticamente (en la tradición cristiana-judía) dar nombre a las cosas, es decir, llamarlas desde su ausencia, de su insignificancia, de su falta de sentido, hacerlas otra vez presentes, vivas con efectos, de los cuales el sujeto hablante tenga conciencia y correspondencia.

La lectura de lo literario nos enseña a llamar aquí y ahora, a la luna con los versos de García Lorca, "luna, luna, luna..." ; nos permite llamar a la intimidad aquello que está con nosotros y que otros no ven, cuando la palabra "saudade" (más que nostalgia) lo trae de la distancia; la lectura tiene un privilegio que es presentar al mundo desnudo de las viejas escrituras, de las ideologías marcadas en su producción, desnudo de la letra muerta, de la escritura paralizante, determinada por una razón exterior y extraña a la persona viva hasta que esta pueda traerla a la vida con su propia sangre, su propio vigor.

Sería justo y necesario decir que las lecturas nuevas, actualizadas en cada uno no pueden y no consiguen por sí mismas hacer tabla rasa de todo aquello que ya antes fue leído y escrito sobre el mundo. Son seis milenios de lecturas y escrituras en la tentativa de entendernos y organizarnos. Pues para alcanzar nuevas lecturas así, en el plural, es necesario buscar nuevas humanidades y fundar nuevas democracias. $\mathrm{O}$ al revés? Las nuevas lecturas son las pueden crear nuevas humanidades 
y fundar nuevas democracias. Llego al plural que señalé en el título de la conferencia y para extender, o mejor, problematizar esta cuestión de grado, voy a recorrer a la mayor transformación que hubo en el campo de la teoría del lenguaje y de la literatura en este siglo: el paso dado de la producción a la recepción de textos como énfasis de los estudios teóricos del autor al lector, con la idea de que el mundo no estaría en la palabra escrita del autor pero en la palabra reconstruida por los lectores como dijeron Sartre, Jauss e Iser. O quizás, en la deconstrucción, según Derrida, Rorty y otros.

Esto explica por qué Borges podía decir que se enorgullecía más de los libros que había leído que de los que había escrito. La escritura es solitaria, la lectura es el ingreso en una comunidad de lectores, crea solidaridades. No era sólo un juego de palabras. En lo que estaba escrito encontraba un diálogo o una polémica y se creia en muy buena compañía como lector de mundo y de vidas escritas. Es importante que nos presentemos como lectores pues esto habla de nosotros, con quién "vamos", con quién nos "con-movemos". Es bien cierto que Aristóteles ya lo había señalado en algún aspecto cuando formalizó el concepto de catarsis apuntando el efecto de realidad que tienen las palabras sobre las personas. La cuestión desliza del desciframiento del mundo que estaba en la escrita a la construcción del mundo que está en la lectura: una es pasado, otra es presente.

Además, la lectura es única, a cada vez; aun para el mismo lector, delante del mismo texto. Al vivirla, cambiamos y luego cambiamos nuestra lectura, que no pierde lo vivido; sino, que se le acrecienta lo vivo, lo nuevo: son muchas nas lecturas que, incluso, de algún modo afectan a los propios textos. Quizás no haya cómo considerar a ciertos autores, ciertas escrituras sin mencionar a ciertos lectores/ ciertos críticos que los convocaron a la luz del mundo, al tramar su relación con la vida, con otros nuevos tiempos. Esto es propio del lector, actualizar lo escrito. El autor, decía el ingenioso lector Roland Barthes, "después del punto final, el autor está muerto" y sólo sobrevivirá a los ojos de un lector. Es el lector quien le recoge de su abandono y le da nueva vida. Libre de la dictadura de la escritura, el hombre puede percibir lo nuevo en el flagrante antiguo que refleja sobre él, y así crear nueva escena y pensar por cuenta propia.

Otra vez, atención: lo que digo no significa desconsiderar lo que los demás piensan; ignorar lo que los otros elaboran, y agregar su propia voz al texto cuya singularidad rompe y suma a un sólo tiempo. La sensibilidad de lo vivido y no sólo de lo argumentado. Vuelva lo legible, dice Barthes, en escribible, ahora por el lector, a partir de su historia de sujeto. Sujeto que no se confunde con sujetado, sometido pero que se alza de donde yace (sub-jactum) y puede aparecer por la voz y palabra propia mientras (se) sorprende, seduce, encanta y hace familiar lo que era extraño. 
En la lectura, somos menos solos; no es gratis el estereotipo del pseudosolitario lector. La palabra personal del lector frente al texto lo expone y lo compromete (de com-promiso, de promesa con) libremente, con lo dicho. Estar comprometido es dar su palabra en fianza de lo que vive; ya no es la palabra del otro que, al principio, podría no tener cualquier sentido, sino la palabra personal que el lector pone en la articulación del texto con el mundo y su vida. Entonces, todo lo humano cambia, porque nuestra diferencia más radical entre todas las cosas creadas es tener voz para expresar lo que va dentro, es tener lenguaje para decir lo nuevo, para hacer lo nuevo, como dueños de un lenguaje creador que no nos somete como las hormigas a un código genético que las determina todas iguales; pero a nosotros nos llena de aire para indicar: Ecce homo!

El lenguaje, la voz, la mano que nos da el poder de decirnos quiénes somos a nosotros mismos, nos humaniza: ser dueño de la propia voz es lo más humano que podemos alcanzar en nuestra parcería de vida con los otros. Implica que tengamos compromiso con la palabra que suena a través de la máscara y que reconocemos como nuestra y firmamos, no en un papel o cinta magnética, sino poder decir yo sabiendo lo que se dice. Volviendo a una razón sensible, abandonando una esquizofrenia que opone cuerpo y alma, razón y sensibilidad, materia y espíritu, para comprender y aceptar nuestra complejidad que no es una u otra cosa, sino una y otra. Las dos.

Salir del automatismo de decir las cosas por decirlas, cuando no tenemos convicción de decirlas: lo humano nos impone estar más cerca, estar más vecinos, la humanidad del oír, del tocar, del mirar aunque la aldea global nos pone cerca de lo lejos y hace de lo cercano lo lejos, por las redes informatizadas. Nada antes nos había aproximado lejano parecer del, al fin y al cabo, todo nos llega por la televisión, vídeo, cintas magnéticas; hoy no nos llega como Cristóbal Colón por barco - llega súbito sin que parezca un invasor. Pero, que no nos separe de lo nuestro, que nos permita invitarlo o no, con un dedo en el teclado del PC. Para tanto hay que elegir, hay que ser lector. Mientras tanto, puede que los más próximos estén dispersos y no hay botón que los haga desaparecer sin emociones, de la pantalla de mi vida. El compromiso recobra su fuerza: somos ciudadanos del mundo pero ni el mundo nos reconoce, ni nosotros él. Sin embargo, en nuestras familias, condominios, comunidades no podemos seguir extraños, como extranjeros - es necesario rescatar un espacio donde nos reconozcan por nuestros nombres propios y nuestras voces. Donde reconozcamos a los demás como otros y pares. Esto no es negación de la aldea global, no significa ignorarla.

Con esto quiero decir que la cuestión de la ciudadanía - que en Grecia implicaba ser libre para levantar la voz en la plaza, según el juicio de los propios hombres llamados libres - es hoy más compleja: aquella ya no nos sirve, pues llega hasta el siglo XIX, agoniza en el XX y no cambia al mundo.

Ayer hubo una marcha por la paz en Colombia: estaba em Bogotá y me sentí obligada a asistir pues no era sólo una marcha de colombianos apenas, era una 
marcha de los hombres en busca de la libre expresión, de la igualdad y de la fraternidad perdida, en medio de la multitud de rostros que son máscaras. Con la intención de encontrar una gran tribu sin fronteras y de muchas banderas hermanadas, caminábamos. Sin embargo, me sorprendí al escuchar una voz que decía querer "separarse de este grupo de personas", refiriéndose a aquellos que nos alcanzaban y que venían atrás. Asi estamos: no sabemos lo que queremos (la paz) porque no sabemos quiénes somos, por incapacidad del diálogo, de intercambio, del contrapunto que la lectura ofrece, en lugar de las afirmaciones autorales. Esforzarse para que las diferencias puedan caminar juntas, pues de esta tolerancia y no de la dominación y aniquilamiento nace el equilibrio y la armonía: esto nos falta. ¿Qué bandera habría para empujar a todos hacia adelante? ¿Qué bandera nos impulsaría a todos para la paz?. Son las nuevas humanidades de la tolerancia, lo humano que no se proponga como única forma modelar, como una receta; lo humano más delicado con el dolor, con lo feo, con el loco, con el pobre. Descubrir, no que la libertad termina cuando comienza la del otro, sino que la libertad es el comienzo del compromiso con el otro - es por eso que somos libres para ser totalmente enteros y complementariamente distintos.

Quiero decir que lo humano tiene en su condición inenarrable una estética y una ética, nos cobra belleza y armonía que viene de lo múltiple, de lo plural; entonces, las democracias también necesitan ser plurales. Las nuevas tribus, según Maffesoli, no son un retorno a la barbarie, a lo primitivo sino una transfiguración de lo político- el poder conducido por el interés común por encima de los privados, por el diálogo compartido y respetuoso - que nada tiene de moralismo sectario y excluyente: cuando en una marcha por la paz no toleramos banderas diversas, cuando en un salón no toleramos ideas diferentes sin obligarnos a ellas, no hay humanidades y no habrá democracias: están las mujeres, los niños, los negros, los homosexuales, los miserables a la búsqueda de quien los oiga, quien los entienda, para con el diálogo salir de la opresión; buscan a alguíen que quiera saber de sus necesidades, particularidades para alcanzar el derecho a la vida, sin descreencias y sin mutilaciones.

Lo que nace ahora debe ser plural o no va a sobrevivir: necesitamos mucho más de socialidad que de sociedad, mucho menos de ser socios con ventajas que compañeros de propiedad - el intercambio de amabilidades se volvió extraño o hipócrita por la seguridad que tenemos en nuestras miserables verdades con respeto al otro que está callado. Necesitamos de más humildad para admitir las inseguridades y las limitaciones que dispensan el juicio hecho, por nosotros. Solamente rescatando la razón sensible, lo razonable y amable es que alcanzaremos a ser una comunidad singular. Singular no porque sea única sino porque es plural; que escoge formas de convivencia y no de violencia; donde se escucha, donde hay palabras, donde hay espacio para el gesto del cuerpo para confirmar en los hechos lo que las palabras encubren. 
La lectura personal pero compartida es paciente porque sufre y espera el dolor de la incomprensión. El tránsito, es decir, el paso (la pasión) de un acto a otro, crea esta interacción amorosa en la cual se va tejiendo el texto social con su responsabilidad. Responsabilidad etimologicamente tiene la misma raíz de respuesta. Entonces, al creador de la palabra le compete saber que ella es respuesta - y responsable por lo que sigue, por lo que desencadena; la palabra se com-promete con los demás, compromiso que quizás nos pueda alejar de la violencia que aniquila al otro, aplastra al otro, deshace al otro. La lectura es siempre respuesta a una pergunta que nos propone un texto en un lenguaje cualquiera.

Miramos la palabra Yo, reclamada para expresar al sujeto hablante: es una palabra mágica porque a cada vez solamente una persona puede pronunciarla y aun así ella , la palabra $Y o$, no es exclusivamente de uno. Cuando alquien dice $Y o$, es su tiempo de hablar y el mío de callar; luego la palabra es mía, cuando retomo el Yo, mientras el otro escucha. Una palabra que perteneciendo a todos, solamente uno puede usarla cada vez: la misma palabra rescata vez a vez, a otro sujeto singular, otro pensar, otro sentir, otro querer. Luego la palabra Yo vuelve, retorna a quien toma la palabra en la cadena ilimitada del diálogo para que NADIE pueda decir Yo para siempre, a riesgo de erigirse en Dios.

Esta es la magia que, aprendiendo a leer, a dominar el lenguaje, nos permitimos realizar: siendo singular está en el plural, pues la lectura es el permanente paso de la palabra de uno a otro, por la interacción desautomatizada que realiza, donde el "yo" ausente del otro/autor me pide una respuesta personal que me permita también decir yo, en el compromiso que tengo con mi palabra y la suya. Leer no es pues tan sencillo como descifrar letras en la página del libro didáctico y para quien supiese, de hecho, leer/ser, estudiar se asemejaría a un juego instigante donde saber sería saberse y conocer el mundo y al otro.

Para terminar, quería pedir le prestado a Eduardo Galeano una crónica reciente -"Al borde del tercer milenio" - en que revela esta libertad y responsabilidad de ser lector. Quiero así saludar latinoamericanamente a los de la tierra de García Máquez, donde, todavía, "no hay quien le escriba al coronel".

Con Galeano, hago en esta narración oral, un voto de que a cada texto seamos lectores más intensos y extensivos a punto de entonces sí, poder escribirnos e inscribirnos en la palabra leída, la que rescate y regenere (génesis) nuestras humanidades olvidadas o desconocidas:

Ya está naciendo el nuevo milenio. No se puede tomar el asunto demasiado en serio: al fin y al cabo, el año 2001 de los cristianos es el año 1379 de los musulmanes, el 5114 de los mayas y el 5762 de los judíos.

El nuevo milenio nace un primero de enero por obra y gracia de un capricho de los senadores del imperio romano, que un buen día decidieron romper la tradición que mandaba celebrar el año neuvo en el comienzo de la primavera y la cuenta de los años de la era cristiana proviene de otro capricho: un buen día, el papa de 
Roma decidió poner fecha al nacimiento de Jesús, aunque nadie sabe cuándo nació.

El tiempo se burla de los límites que le inventamos para creernos el cuento de que él nos obedece; pero el mundo entero celebra y teme esta frontera. Una invitación al vuelo. Milenio va, milenio viene, la ocasión es propicia para que los oradores de inflamada verba peroren sobre el destino de la humanidad, y para que los voceros de la ira de Dios anuncien el fin del mundo y la reventazón general, mientras el tiempo continúa, calladito la boca, su caminata a lo largo de la eternidad y del misterio. La verdad sea dicha, no hay quien resista: en una fecha así, por arbitraria que sea, cualquiera siente la tentación de preguntarse cómo será el tiempo que será. Y vaya uno a saber cómo será.

Tenemos una única certeza: en el siglo veintiuno, si todavia estamos aquí, todos nosotros seremos gente del siglo pasado $y$, peor, seremos gente del pasado milenio. Aunque no podemos adivinar el tiempo que será, sí que tenemos, al menos, el derecho de imaginar el que queremos que sea. En 1948 y en 1976, las Naciones Unidas proclamaron extensas listas de derechos humanos; pero la inmensa mayoría de la humanidad no tiene más que el derecho de ver, oír y callar. ¿Qué tal si empezamos a ejercer el jamás proclamado derecho de soñar? ¿Qué tal si deliramos por un ratito?

Vamos a clavar los ojos más allá de la infamia, para adivinar otro mundo posible: el aire estará limpio de todo veneno que no venga de los miedos humanos y de las humanas pasiones; en las calles, los automóviles serán aplastados por los perros; la gente no será manejada por el automóvil, ni será programada por la computadora, ni será comprada por el supermercado, ni será mirada por el televisor; el televisor dejará de ser el miembro más importante de la familia, y será tratado como la plancha o el lavarropas; la gente trabajará para vivir, en lugar de vivir para trabajar; se incorporará a los códigos penales el delito de estupidez, que cometen quienes viven por tener o por ganar, en vez de vivir por vivir nomás, como canta el pájaro sin saber que canta y como juega el niño sin saber que juega; en ningún país irán presos los muchachos que nieguen a cumplir el servicio militar, sino los que quieran cumplirlo; los economistas no llamarán nivel de vida al nivel de consumo, ni llamarán calidad de vida a la cantidad de cosas; los cocineros no creerán que a las langostas les encanta que las hiervan vivas; los políticos no creerán que a los países les encanta ser invadidos; los políticos no creerán que a los pobres les encanta comer promesas; la solemnidad se dejará de creer que es una virtud, y nadie tomará en serio a nadie que no sea capaz de tomarse el pelo; la muerte y el dinero perderán sus mágicos poderes, y ni por defunción ni por fortuna se convertirá el canalla en virtuoso caballero; nadie será considerado héroe ni tonto por hacer lo que cree justo en lugar de hacer lo que más le conviene; el mundo ya no estará en guerra contra los pobres, sino contra la pobreza, y la industria militar no tendrá más remedio que declararse en quiebra; la comida no será una mercancía, ni la comunicación un negocio, porque la comida y la comunicación son derechos humanos; nadie morirá de hambre, 
porque nadie morirá de indigestión; los ninõs de la calle no serán tratados como basura, porque no habrá niños de la calle; los niños ricos no serán tatados como si fueran dinero, porque no habrá niños ricos; la educación no será el privilegio de quienes puedan pagarla; la policía no será la maldición de quienes no puedan comprarla; la justicia y la libertad, hermanas siamesas condenadas a vivir separadas, volverán a juntarse, bien pegaditas, espalda contra espalda; una mujer, negra, será presidenta de Brasil y otra mujer, negra, será presidenta de los Estados Unidos de América; una mujer india gobernará Guatemala y otra, Perú; en Argentina, las locas de Plaza de Mayo serán un ejemplo de salud mental, porque ellas se negaron a olvidar en los tiempos de la amnesia obligatoria; la Santa Madre Iglesia corregirá las erratas de las tablas de Moisés, y también dictará otro mandamiento, que se le había olvidado a Dios: "Amarás a la naturaleza, de la que formas parte"; serán reforestados los desiertos del mundo y los desiertos del alma: los desesperados serán esperados y los perdidos serán encontrados, porque ellos son los que se desesperaron de tanto esperar y los que se perdieron de tanto buscar; seremos compatriotas y contemporáneos de todos los que tengan voluntad de justicia y voluntad de belleza, hayan nacido donde hayan nacido y hayan vivido cuando hayan vivido, sin que importen ni un poquito las fronteras del mapa o del tiempo; puede que la perfección siga siendo el aburrido privilegio de los dioses; pero en este mundo chambón y jodido, cada noche será vivida como si fuera la última y cada día como si fuera el primero.

\section{RESUMO}

Na pós-modernidade de individualismo e massificação, a experiência da leitura, em sua prática solidária, com uma nova pedagogia dos afetos, substituindo a opressão das certezas prévias, pode ser um recurso extraordinário para que se construa uma ética de respeito às diferenças, onde a singularidade dos sujeitos não perca de vista a pluraridade dos enfoques e das necessidades específicas em busca da tolerância e da delicadeza que todos reclamamos.

Palavras-chave: leitura, subjetividade, narratividade. 
YUNES, Eliana Lectures, Hombres y Democracias

\section{ABSTRACT}

In postmodern times where individualism and massification are rules, the experience of reading in a new responssible practice, supported by a pedagogy of affections which shall substitute the opressive feeling of previons certitudes, can be a stimulus to buld ethical relationship among differences - then, the singularity of the readers might help not to lose sight of the plurality of views, looking foward the tolerant audience and gentleness we are longing for.

Key words: reading, subjectivity, narrativity. 